Article

\title{
Exploring the Intersections of Emotional Solidarity and Ethic of Care: An Analysis of Their Synergistic Contributions to Sustainable Community Tourism Development
}

\author{
Tek B. Dangi
}

Department of Recreation, Park and Tourism Sciences, Texas A\&M University, College Station, TX 77843, USA; tekdangi@gmail.com; Tel.: +1-(307)-460-1892

Received: 23 July 2018; Accepted: 30 July 2018; Published: 1 August 2018

\begin{abstract}
Interactions between tourists and residents have been interpreted and analyzed applying various theoretical lenses. One of such lens is the study of perception of emotional solidarity forged between individuals based on inter-dependent activities and another is the application of lens of ethic of care, which suggests developing synergetic relationships between individuals based on mutual respect, a caring attitude, and understanding that is marked by equality of relations. No research to date has attempted to examine how these two theoretical constructs complement one another. The study explored how integrating the intersections of two complementary constructs-Emotional Solidarity (ES) and Ethic of Care (EC) could potentially contribute to enhancing stakeholders-tourists interactions, and subsequently contribute to sustainable tourism development. The study applied a mixed qualitative research blending emergent data with theory driven data conducting semi-structured interviews with 40 tourism stakeholders in Bryan-College Station (BCS), Texas. The study findings suggest that tourism contributed to fostering cultural pride and respect; sharing the diverse history and culture of BCS with tourists filled with ethic of care; and, enhanced tourism stakeholders' perceptions of emotional solidarity with tourists and residents alike. The study suggested the need for strong interconnections between ES and EC theories and emphasized their synergistic application in BCS tourism in particular and sustainable tourism in general.
\end{abstract}

Keywords: emotional solidarity; ethics; ethic of care; ethical tourism; justice tourism; tourists; tourism stakeholders

\section{Introduction}

Interactions between tourists and residents have been interpreted and analyzed while applying various theoretical lenses. One such lens is the perception of emotional solidarity forged between individuals based on interdependent activities [1,2]. Other scholars (e.g., [3-7]) have attempted to define such tourist-resident interactions applying the lens of ethic of care, which suggests developing synergetic relationships between individuals based on mutual respect, a caring attitude and understanding marked by equality of relations. No research to date has attempted to examine how these two theoretical constructs complement one another. This research seeks to do so within the context of sustainable tourism.

Emotional solidarity (ES) is interpreted as a feeling of closeness or bonding that individuals experience with one another. Based on Durkheim's theory of emotional solidarity, Woosnam, Norman, and Ying [2] proposed that residents' shared beliefs, shared behavior, and interaction with tourists significantly predicted their emotional solidarity with those that are visiting their community. 
Some scholars equate ethic of care (EC) with ethical tourism or justice tourism. For example, Hultsman [8] stated that justice tourism is what is virtuous, moral, and ethical. Smith and Duffy [7] and Jamal, Camargo, and Wilson [4] emphasized the notion of ethic of care in sustainable community tourism settings to guide resident-tourist interactions filled with respect for diversity, recognition, tolerance, inclusiveness, and a caring attitude. Ethic of care is specifically mentioned in terms of having a caring attitude and a spirit to consider the needs of others [6] guided by virtue and respect for persons and place [9] — each of which are considered requisites of ethical or justice tourism [7]. Smith and Duffy [7] argued that tourism could not be sustainable without addressing the issues of disadvantaged with ethic of care and justice.

From a brief review of the literature, it becomes apparent that numerous aspects of ES and EC potentially complement one another. EC mainly denotes respect, recognition, equality, justice, fairness, concern, and respect for others $[3,6,7]$, which come very close to the dimensions of emotional solidarity, including sympathetic understanding, emotional closeness, and welcoming nature manifested through shared beliefs, shared behavior, and interactions [10]. As can be seen, the key elements of EC seem to be achieved through the exchange of shared beliefs, shared behavior, and interaction between residents and tourists as long as residents and guests respect their diversity and differences, yet engage in a friendly dialogue with mutual understanding, mutual respect, and relationship marked by equality, as outlined in justice tourism [11].

Notwithstanding the contribution of ES theory and the Emotional Solidarity Scale (ESS) [10], no study within the sustainable tourism literature has explored the linkages between ES and EC. Exploration of intersections between these two complementary constructs could potentially contribute to enhancing resident-tourist interactions and subsequently contribute to sustainable tourism development. Therefore, the purpose of the study is to explore the linkages between ES and $\mathrm{EC}$, and to exemplify through qualitative research how these two interrelated notions, when linked together, have the potential to enhance interactions between tourism stakeholders and tourists and to contribute to sustainable community tourism development.

To explore these linkages between ES and EC, a community tourism setting of Bryan-College Station (BCS) in Texas was chosen. Forty tourism stakeholders representing various forms of tourism governance, businesses, and community organizations participated in semi-structured interviews and expressed their perceptions about those issues. The overarching research question relating to ethic of care (bifurcated in EC and ES), which guided the study was: How do the various tourism stakeholders feel about tourism development in BCS, specifically, with respect to: (a) an ethic of care, and (b) the perception of emotional solidarity between tourism stakeholders and tourists?

In relation to ethic of care (EC), the study found that tourism helped to foster cultural pride and respect in BCS. Festivals and events contributed to the preservation and promotion of various ethnic heritages, provided tourists a platform for interacting with locals and economic opportunities for local residents. The study found that BCS tourism stakeholders cared about educating tourists about the diverse history and culture of the BCS in a respectful, fair, caring, and ethical manner. In turn, tourists showed interest in BCS culture, heritage, and cuisine, as manifested through repeat visits and participation in heritage/cultural activities. Further, the study suggested the perception of emotional solidarity (ES) between the tourism stakeholders (all types of hosts) and tourists (both local and out of the state) was suggested to be rather strong in the BCS. Stakeholders believed that they developed 'family ties' with tourists and tourists felt close, connected and bonded with the people and place in BCS. Since no past researchers explored the complementary qualities of ES and EC, the primary contribution of this study lies in applying together the concepts of emotional solidarity and ethic of care to enhance stakeholder-tourist interactions. Furthermore, the contribution of this research lies in the form of recommendations to tourism policy makers and marketers to embrace both ES and EC in a complementary way, which have far-reaching positive implications to sustainable community tourism development through the promotion of positive tourists-stakeholders/residents interactions. 


\section{Literature Review}

\subsection{Emotional Solidarity}

Resident-tourist interactions have been marked by a transitory nature, unbalanced relationships, lack of spontaneity, and constraints that are imposed by time and space [12,13]. Others have defined such interactions by financial exchanges applying theories, such as social exchange theory [14,15]. However, in recent years, research works undertaken by Woosnam and colleagues $[10,16,17]$ have established that tourist-host interactions can be analyzed beyond relations of reciprocity and financial transactions.

Emotional solidarity has been defined as a feeling of closeness or bonding that individuals experience with one another. Based on Durkheim's theory of emotional solidarity ([1915] 1995), [18] Woosnam, Norman, and Ying [2] proposed that the construct emerges from a degree of shared beliefs, shared behavior, and interaction among individuals. Following a qualitative study undertaken by Woosnam, Norman and Ying [2] on the theoretical framework of emotional solidarity, Woosnam and Norman [10] subsequently developed the Emotional Solidarity Scale (ESS), comprised of three factors: welcoming nature; emotional closeness; and, sympathetic understanding. Woosnam [1] first tested the model of emotional solidarity of community residents with tourists in Beaufort County, South Carolina and demonstrated how the three antecedents significantly predicted each of the ESS factors. Among those antecedents, shared beliefs and interaction explained the highest degree of variance in solidarity.

In a succeeding study of Galveston County, TX, Woosnam [16] compared residents' and tourists' emotional solidarity with one another, which was the first of its type as previous studies were limited in studying residents' perceptions of emotional solidarity with tourists. The findings of the study suggested that a positive degree of emotional solidarity existed between residents and tourists, most notably across the welcoming nature and sympathetic understanding factors [16]. Woosnam [1] conducted another study in Galveston County, which followed a two-step process while using the ESS factors to predict levels of the Tourism Impact Attitude Scale (TIAS) and its two factors (support for tourism development and contributions tourism makes to the community). The study found that, collectively, each of the three ESS factors significantly predicted the two TIAS factors, with sympathetic understanding explaining the perceived impacts best [1].

Emotional solidarity has also been examined in contexts outside of the U.S. Woosnam, Maruyama, and Boley [19] tested the three-dimensional factor structure of the ESS in Oizumi, Japan between a Brazilian ethnic minority group and the dominant Japanese ethnic group. The study findings demonstrated widespread applicability of the scale within an international context. In another notable study testing the ESS scale between tourists and residents in the context of Osun Osogbo Sacred Grove and the annual Osun Osogbo Festival in Osogbo, Nigeria, Woosnam, Aleshinloye, and Maruyama [20] found that residents and tourists reported significant, yet different, levels of emotional solidarity on two of the three ESS factors (e.g., emotional closeness and sympathetic understanding). For example, tourists expressed a significantly higher degree of solidarity with residents than residents did with tourists. In a recent study of Cape Verde Islands (off the western coast of Africa), Ribeiro, Woosnam, Pinto, and Silva [21] proposed a theoretical model integrating two lines of tourism research accessing the relationships between tourists' emotional solidarity with residents and destination loyalty and satisfaction. The results suggested that tourists' feeling welcomed by residents and sympathetic understanding with residents directly influenced destination loyalty. Further, the three dimensions of emotional solidarity were all mediated by satisfaction [21]. Woosnam and colleagues have offered a novel theoretical framework for examining intimate relationships between the residents and tourists, which as Woosnam [1] suggested, should be considered in both developed and developing tourist destinations. The following discussion first defines ethical/justice tourism and the notion of EC, and it then relates how the notion of ethical/justice tourism (EC) is interconnected with emotional solidarity (ES). 


\subsection{Ethical/Justice Tourism and the Notion of Ethic of Care (EC)}

Ethical tourism: A review of the tourism literature exemplifies strong inter-connections between the ethical and justice/just tourism. Justice in tourism can be theoretically grounded as ethical tourism and/or just/justice tourism as Hultsman [8] conceptualized ethicality as "just tourism" and further stated that "just tourism" is what is virtuous, moral, and ethical. Hultsamn stated ethics should be viewed as both a "philosophical inquiry into values and as practical application of moral behavior" [8] (p. 554). Tribe [22] concurred that ethics provides the broader disciplinary framework for various types of tourism, including sustainable tourism. Ethical tourism action is not only the philosophical understanding of what is good and just in and for tourism, but also further requires good action. Tribe [22] borrowed the notion of phronesis (translated as practical knowledge/judgment) from Aristotle to help understand ethics. Further, it is argued that guided by practical wisdom, ethical tourism actions should take responsibility for sustaining tourism stewardship in societies. Concerning the import of ethics in sustainable tourism, Macbeth [23] attested, "Ethics is a simple imperative for living a moral life: informing all actions are ethical distinctions and decisions, values" [23] (p. 963). Macbeth [23] further added to Jafari's [24] four platforms of tourism development (i.e., advocacy, cautionary, adaptancy, knowledge-based) and proposed sustainability and ethics as the fifth and sixth platforms, respectively.

In Ethics of Tourism, Lovelock and Lovelock [5] mentioned the need for applying an ethical approach in a broader scale in connection with the consumers, the environment, with people in poverty including the indigenous people. Lovelock and Lovelock [5] considered the usage of 'ethics' and 'tourism' together as a new phenomenon; however, to make tourism more sustainable, these authors suggested an approach that embraces ethics beyond the three pillars (environmental, economic, and social-cultural) of sustainability, as outlined by many authors [7-9,22,23,25-29].

Despite the urgency of embracing ethicality in tourism operations, no uniform definition of 'ethical tourism' exists. It is sometimes associated with alternative forms of tourism, such as sustainable tourism, ecotourism, responsible tourism, just/justice tourism, pro-poor tourism, Fair Trade Tourism in South Africa (FTTSA, which also pays attention to human rights issues), and so forth [3,5,30]. The Cape Town Declaration on Responsible Tourism emphasizes the form of tourism as responsible that is "culturally sensitive, engenders respect between tourists and hosts, and builds local pride and confidence" [5] (p. 26). Viewed from the multiple lenses discussed above, it can be argued that many alternative forms of tourism are closer to ethical tourism practices. Lovelock and Lovelock [5] provided a more pragmatic definition of ethical tourism to move forward:

Ethical tourism is tourism in which all stakeholders involved apply principles of good behavior (justice, fairness and equality), to their interactions with one another, with society, with the environment and other life forms. [5] (p. 31)

This is how ethical tourism has common elements with justice tourism, such as building solidarity between tourists and residents based on equality, respect, and mutual understanding [11,28]. Further, Lovelock and Lovelock [5] argued ethical tourism as more progressive as it incorporates humanistic elements of telling hosts and guests how they should behave to one another in a respectful way while being aware of any negative impacts. This is how ethical tourism places special emphasis on an ethic of care to people, places, and the cultures visited [4], and on reciprocal behavior that is based on mutual respect and understanding $[11,28,29]$. These features are reflected in the context of ES in the form of sympathetic understanding, emotional closeness, and welcoming nature to tourists [2,10]. Further, it is emphasized that ethical tourism is more than following a process, adhering to laws and regulations, but it is a way of thinking and acting from the perspective of an 'ethic' or with more responsibility. Ethical tourism is "about being a moral-being rather than a 'green-being', or a 'justice-being', or and 'eco-being'”, Lovelock and Lovelock [5] (p. 35) stated.

Justice Tourism. Many scholars have defined justice tourism based on the central notion of ethical and equitable operations and interactions. Lee and Jamal [31] (p. 46) referred to Aristotle 
stating, "Just behavior is virtuous behavior, and fairness in society (or community)". Similarly, Higgins-Desbiolles [28] argued that justice tourism "seeks to reform the inequities and damages of contemporary tourism ... to chart a path to a more just global order" [28] (p. 345). Scheyvens [11] described justice tourism as "both ethical and equitable" [11] (p. 104), which consists of attributes such as solidarity, mutual understanding, equality, and respect (detailed in Table 1). Smith and Duffy [7], championed social justice and ethical values over modernity and development that prioritized economic values, and they suggested ethical tourism as a means to limit such imbalanced growth. Higgins-Desbiolles [28] argued for justice tourism as the only true form of alternative tourism because it has the capability of thwarting capitalists" interests as "it seeks to reform the inequities and damages of contemporary tourism ... to chart a path to a more just global order" [28] (p. 345), by developing responsible relationships between hosts and guests.

Fennell [3] conceived of justice tourism as a form of ethical tourism given it attempts to bring a sense of fairness to tourism exchanges. Fennell [3] further posited that Rawls' [32,33] renewed normative ethical theories of the 1970s and 1980s, "corresponding with the movements in both environmental justice and business ethics" [3] (p. 100). Rawls' [32] A Theory of Justice is premised on the notion that the very absence of justice threatens the stability of a community and society, thus obstructing its path to progress and prosperity based on the two principles of justice: equal basic liberties to all and fair equality of opportunity. Fennell [3] forwarded a scenario where traditional/minority communities are displaced from their places and means of living to create room for tourism development without adequate compensation or they are excluded from environmental decision-making with neglect to social justice.

Ethic of care. Emerging from the work of justice tourism is the concept of ethic of care, which speaks to the balance between human agency and the socio-cultural environment [3]. Ultimately, tourism activities should be operated in such a way that maintain and perpetuate the integrity of our social, cultural, and natural heritage, paying attention and care to people and to the places visited. Jamal, Camargo, and Wilson [4] considered the concept to be caring about the "Other" and incorporating respect for diversity and tolerance within the justice framework. Fennell [3] further claimed whereas morality focuses on fairness and justice, ethic of care embodies and adds "other philosophical elements such as character and emotion" [3] (p. 260). The Josephson Institute developed 12 Ethical Principles for Business Executives, among which are a Concern for Others and Respect for Others. Though not written exclusively for the tourism and hospitality industries, such principles go far within community tourism settings to: (1) consider the needs of locals, and (2) enhance more positive interactions between hosts and guests [34].

It should be mentioned that while the three theoretical notions of emotional solidarity, ethic of care, and ethical/justice tourism are similar, they are not identical. Rather, the study demonstrates how some common elements prevalent in each domain can better complement one another and improve overall tourist experiences in a destination while benefitting the resident communities. Presenting a comprehensive outline of moral principles framework, Schumann [35] claims ethic of care to be the morally correct action that expresses care in protecting the special relationships individuals have with each other. Such individuals may take the form of family members, friends, or coworkers. Through an ethic of care, relationships are nurtured and any sense of domination or disrespect is greatly reduced [35].

Nurturing and caring relations could equally be applied in tourism settings where hosts and guests form relations through business, shared understandings, and interactions. The UNWTO [36] reinforces ethical and caring behaviors among residents and tourists through 10 specific articles of a Global Code of Ethics for Tourism. Article 1 of the code emphasizes contribution of tourism to "mutual understanding and respect between peoples and societies" [36], and Article 5 identifies tourism as a beneficial activity for host communities/countries. Other codes of conduct also highlight the responsibilities of hosts, local governments, and tourists to make tourism a sustainable business benefiting all. Lovelock and Lovelock [5] have mentioned that ethic of care is not about establishing generalized laws; rather, "it is about developing an understanding and concern for those involved. 
The emphasis is on the relational nature of identity and requires us to be aware of the needs of others and to act on this awareness" [5] (p. 83).

In reviewing the pertinent literature on ethic of care and emotional solidarity, it seems that these notions are inextricably interconnected. Further, ethic of care underlines the importance for paying attention to moral, virtuous, and ethical actions for and in tourism, whereas the dimensions of emotional solidarity such as shared beliefs, shared behavior, and interaction facilitate emotional closeness, sympathetic understanding, and welcoming nature between residents and tourists. As such, the former is complemented by the latter in considering justice, fairness, equality, caring attitude, and respect. In spite of such complementary factors existing between ethic of care and emotional solidarity, no study has been undertaken integrating these constructs. The current study explores this integration (as summarized in Table 1 below) and provides both theoretical and practical implications within the context of sustainable community tourism in efforts to ultimately enhance host-guest interactions.

Table 1. Summary of defining elements of emotional solidarity, ethical/justice tourism, and ethic of care as per various sources.

\begin{tabular}{|c|c|}
\hline Concepts & Definitions/Elements \\
\hline Emotional solidarity & $\begin{array}{l}\text { - Feeling of closeness or bonding that individuals experience with one } \\
\text { another-Durkheim's theory of emotional solidarity [18]. } \\
\text { - Shared beliefs, shared behavior and interaction lead to emotional closeness, } \\
\text { sympathetic understanding, and welcoming nature }[2,10] \text {. }\end{array}$ \\
\hline \multirow[b]{2}{*}{$\begin{array}{l}\text { Ethical/Justice tourism } \\
\text { and ethic of care }\end{array}$} & $\begin{array}{l}\text { Ethical/justice tourism: } \\
\text { - Virtuous, moral and ethical tourism [8]. } \\
\text { - Just/virtuous behavior, and fairness in society [31]. } \\
\text { - Embodiment of phronesis that included "knowledge; 'the good' actions, } \\
\text { and practices" [22] (p. 134). } \\
\text { - Living a moral life, informing all decisions and actions as ethical [23]. } \\
\text { - Justice tourism is "both ethical and equitable", and it consisted of attributes, } \\
\text { it: "(1) builds solidarity between tourists and those visited; (2) promotes } \\
\text { mutual understanding, and relationship based on equality, sharing and } \\
\text { respect; (3) supports self-sufficiency and self-determination of local } \\
\text { communities; and (4) maximizes local economic, cultural and social } \\
\text { benefits" [11] (p. 104). } \\
\text { Justice tourism is about increasing the depth of solidarity between tourists } \\
\text { and hosts and to develop responsible relationships between them [29]. }\end{array}$ \\
\hline & $\begin{array}{l}\text { Ethic of care: } \\
\text { - "Stakeholders involved apply principles of good behavior (justice, fairness } \\
\text { and equality), to their interactions with one another" ([5] (p. 31)). } \\
\text { "Developing an understanding and concern for those involved. } \\
\text { The emphasis is on the relational nature of identity and requires us to be } \\
\text { aware of the needs of others and to act on this awareness" [5] (p. 83). } \\
\text { Ethic of care expresses care in protecting the special relationships that } \\
\text { individuals have with each other [35]. } \\
\text { - Ethic of care denotes a caring attitude and a spirit to consider the needs of } \\
\text { others [6], guided by virtue and respect for persons and place [9]. } \\
\text { Ethic of care incorporates fairness, concern for others/compassionate, equal } \\
\text { respect for others, least harm and greatest positive good [34]. } \\
\text { Ethic of care denotes "respect for diversity, recognition of difference ... } \\
\text { support of social differentiation and diversity, sympathy, mercy, } \\
\text { forgiveness, tolerance, and inclusiveness" [4] (p. 4903). } \\
\text { Tourism as a beneficial activity for host communities; and "Mutual } \\
\text { understanding and respect between peoples and societies" [36]. }\end{array}$ \\
\hline $\begin{array}{l}\text { Common elements } \\
\text { found in emotional } \\
\text { solidarity-ES and ethic } \\
\text { of care-EC (which can } \\
\text { complement one another) }\end{array}$ & $\begin{array}{l}\text { - Solidarity between tourists and stakeholders/residents; mutual } \\
\text { understanding and relationship based on equality, sharing, and respect. } \\
\text { Shared beliefs, shared behavior, and interactions between } \\
\text { stakeholders/residents and tourists help promote emotional closeness, } \\
\text { sympathetic understanding and welcome nature to tourists. } \\
\text { - Applying good, virtuous, ethical, just and caring behaviors and actions in } \\
\text { tourism interactions/transactions relating to ethic of care. }\end{array}$ \\
\hline
\end{tabular}


Table 1 summarizes the main concepts surrounding emotional solidarity, ethical/justice tourism, and ethic of care. It should be noted that ethic of care is a distinct dimension of ethical/justice tourism that emphasizes the interactions between guests and hosts based on equality, mutual respect, and understanding. As such, these ideals ensure mutually respectful behaviors and inter-relationships among hosts and tourists, which is championed in the perception of emotional solidarity.

Based on the overarching research question (How do the various tourism stakeholders feel about tourism development in BCS, specifically, with respect to: (a) an ethic of care; and, (b) the perception of emotional solidarity between tourism stakeholders and tourists?) four sub-research questions were developed to guide the interviews. The first two questions were directly related to ethic of care and other two questions were directly related to emotional solidarity. These last two questions were guided by the four constructs (i.e., shared beliefs, shared behavior, interaction, and emotional solidarity) within Woosnam and Norman's [10] emotional solidarity theoretical model. The sub-research questions were, as follows:

1. How much attention is being paid to fostering cultural pride and respect for the diverse cultural groups (residents) and traditions in BCS? (Relates to EC).

2. What do you (and other service providers) do to educate the tourists about the diverse history and culture of BCS? (Relates to EC).

3. What is your perception of closeness, mutual understanding, and respect for tourists to BCS? (Relates to ES).

4. What is your perception of closeness, mutual understanding, and respect for residents in relation to tourism development in BCS? (Relates to ES).

\section{Materials and Methods}

\subsection{Study Context}

The twin cities of Bryan-College Station (BCS) within Brazos County, Texas have a tradition of higher education. Texas A\&M University (in College Station), was established in 1876, and it is one of the largest public universities in the nation with over 60,979 student enrollments in fall 2016 on the College Station campus alone [37]. Blinn College, established in 1883, enrolls nearly 19,000 students at the Bryan campus [38]. The twin-cities offer various tourist attractions, including cultural events and festivals, George Bush Presidential Library and Museum, and Historic Downtown Bryan, etc. Among Texas A\&M sports, college football is a primary attraction. Texas A\&M's academic events, such as Graduation Days, Parents' Weekends, and Ring Days also significantly contribute to BCS tourism by drawing a large number of tourists from student family members and the alumni community.

Tourism is a major economic driver for BCS. The Texas Office of the Governor, Economic Development and Tourism [39], Domestic Travel data highlighted that the volume/share of the number of person-stays to the College Station-Bryan MSA was estimated at 4.04 million in 2014, and the volume of person-days was estimated at 7.13 million. A Bryan-College Station Convention and Tourists Bureau report [40], citing Dean Runyan Associates stated, for Texas, tourism is the third largest sector for generating revenues; "It generates $\$ 31.1$ million in tax revenue for Bryan-College Station" and an "estimated 4490 jobs in Bryan-College Station are related to tourism" [40] (pp. 9-13). College football is one of the main stimulators of economy for BCS community which is supported by a study of Oxford Economics [41] stating, "Texas A\&M should never consider taking away its main attraction for the $\mathrm{B} / \mathrm{CS}$ area-A\&M football. It is the greatest tradition of any university in the country ... The total commerce is unbelievable". [41] (p. 24).

\subsection{Study Participants and Design}

Utilizing a purposive snowballing sampling strategy [42], this research involved semi-structured interviews with tourism stakeholders in BCS. Secondary sources of information published (or hosted on websites) from authoritative sources, such as the Bryan College Station Chamber of Commerce and 
the Bryan College Station Convention and Visitors Bureau along with individual participants' business websites were visited to get further information and aid in planning interviews and field visits.

The semi-structured qualitative research questions were guided by underlying theoretical constructs of ethic of care (EC) and four constructs (i.e., shared beliefs, shared behavior, interaction, and emotional solidarity) and many factors of the Emotional Solidarity Scale (ESS) (such as preservation of the area, cultural heritage activities, sympathetic understanding, emotional closeness, welcoming visitors, etc.). However, not all factors that are recommended for quantitative measures of ES could be applied in questions given the nature of the qualitative research (see, [10]). Moreover, through semi-structured interviews utilizing open-ended questions, the research gathered stakeholders' perspective on emotional closeness, interactions, and bonding with the tourists, which emerged as various categories and themes. This mixed-method qualitative research approach was undertaken in an effort to combine both theory-and data-driven themes in arriving at results.

Research participants consisted of a mix of owners, executive and management level employees, operational, and frontline and backstage staff from offices, including city and county offices, businesses, including hotels, motels, and restaurants, and tourism services and community organizations, as detailed in Table 2. Of the 53 participants who were approached for interviews, 40 agreed to participate. Of the 40 participants, 10 were backstage employees, including cooks/chefs and housekeepers specifically from Hispanic and African-American ethnic minorities. Interviews lasted, on average, 45 min and occurred between April 2015 and August 2016.

Table 2. Number and type of research participants.

\begin{tabular}{|c|c|c|}
\hline Participant Types & Participant Names with Identifiers & Category Total \\
\hline Associations & $\begin{array}{l}\text { Convention and Visitors Bureau (CVB \#1), Arts Council } \\
\text { (\#3), Downtown Bryan Association (DBA \#8), Chamber of } \\
\text { Commerce (\#2), and Lodging Association (BVLA \#4) }\end{array}$ & 5 \\
\hline $\begin{array}{l}\text { Restaurants, Hotels } \\
\text { and resorts }\end{array}$ & $\begin{array}{l}\text { Eight restaurants (\#6, 11, 13,14,15, 18, 20, and 21), } \\
\text { and Five hotels and resorts (\#5, 9, 22, 24, and 25) }\end{array}$ & 13 \\
\hline $\begin{array}{l}\text { Community/cultural } \\
\text { organizations }\end{array}$ & $\begin{array}{c}\text { Brazos Valley African American Historical Cultural Society } \\
\text { (BVAAHCS \#17), African-American Museum (AAM \#26), } \\
\text { African-American Church (AAC \#30), Fiesta Patrias (\#16), } \\
\text { Advent GX (\#12) }\end{array}$ & 5 \\
\hline Government offices & $\begin{array}{c}\text { City of Bryan (\#7), City of College Station (\#28), Brazos } \\
\text { County Office (\#23), George Bush Presidential Library and } \\
\text { Museum (GBPLM \#19), and Texas A\&M University } \\
\text { (TAMU) Athletics Department (\#29) }\end{array}$ & 5 \\
\hline Others & Pedi cab (\#10), and Antiques/Art/Crafts shop (\#27) & 2 \\
\hline $\begin{array}{l}\text { Backstage/Back of } \\
\text { the house staffs }\end{array}$ & $\begin{array}{l}\text { Five housekeeping staff at hotels (\#31, 33, 34, } 35 \text { and 36), } \\
\text { and Five hotel/restaurant kitchen staff }(\# 32,37,38,39,40)\end{array}$ & 10 \\
\hline Total Participants & & 40 \\
\hline
\end{tabular}

Participant races: Caucasian (24), Hispanic (8), African-American (8).

A majority of participants $(62.5 \%)$ were male. More than $55 \%$ were in the age group of $41-60$, and a large majority $62.5 \%$ had at least an undergraduate degree. All 39 participants, except one (\#35 who commuted from Navasota), were residents of BCS. Though the study did not target BCS residents on purpose, indirectly, it gathered residents' opinions too as 39/40 stakeholders claimed themselves to be BCS residents.

\subsection{Data Analysis}

The author (who lived in the BCS area for slightly more than five years) also attended five events and festivals in the BCS as a participant observer, which helped in making contacts and understanding the cultural context of the study area. The author transcribed each interview verbatim. Data were analyzed while following an iterative process, which involved moving back and forth 
between the literature and the data to build a theoretically informed picture regarding the issues under exploration. The data analysis process followed the seven typical analytic procedures, as outlined by Marshall and Rossman [43] (p. 206). These steps included: (1) organizing the data; (2) immersion in the data; (3) generating categories and themes; (4) coding the data; (5) offering interpretations through analytic memos; (6) searching for alternative understandings; and, (7) writing the report or other format for presenting the study. However, as defined by Hsieh and Shannon [44] for directed qualitative content analysis, "codes are defined before and during data analysis" and "codes are derived from theory or relevant research findings" [44] (p. 1286), this technique was applied in some instances. Taking coding and analysis guidelines from these authors, codes in the analysis primarily emerged from the research questions (following structural analysis procedures); themes and issues that are inherent in them were established through the literature review. However, to minimize the researcher's knowledge of the field influencing the formation of codes and categories, independent line-by-line coding initially occurred, followed by the development of common categories from the codes under the theme/s and research question/s for the exploration. Common categories derived from the codes were applied to interpret the specific research questions and then to move forward to a discussion. These codes and categories were compared and contrasted across groups and across individual participants to uncover patterns of similarities or differences between emotional solidarity and ethic of care [45,46]. This is how the study applied a mixed-method qualitative data analysis approach, which was undertaken in an effort to combine both theory-and data-driven themes (mixture of deductive and inductive methods) in arriving at results.

\section{Results}

Results of the semi-structured interviews combined with participant observation are presented below. Four overarching themes presenting the intersection of emotional solidarity and ethic of care emerged from the data analysis.

\subsection{Fostering Cultural Pride and Respect Through Tourism}

As part of the emotional solidarity framework [10], shared beliefs encompasses the notion of preserving culture. Such a preservation perspective is central to ethic of care when considering the respect for place and others. Thirty-six of the participants stated that tourism aided in the preservation of heritage through the numerous cultural events and festivals that are held in the BCS. This is evidenced through numerous events centered on the 'Spirit of Aggieland' and perpetuated through Texas A\&M's 'Howdy' welcoming nature. Cultural festivals and events hosted by the Arts Council, the CVB, Downtown Bryan Association, and Texas A\&M University best portrayed their place and cultural heritage. A majority of participants appreciated grant and matching funds made available from the City of Bryan for historic preservation to host these events.

Some participants (\#13 and 14) also expressed that Bryan was cleaner, more accessible, more interesting, and safer than it was 5-10 years ago (\#11 and 13) as a result of sustained tourism growth. Participants from different groups (\#8,14, and 18) agreed that different festivals preserved and promoted the culture and heritage of BCS. Participants \#9 and 25 specifically mentioned that Texas A\&M University (TAMU) traditions and the Aggieland culture dominated BCS as a tourist attraction. Such a perspective was pervasive among officials from the City of College Station and A\&M's Athletics Department. Some participants (\#15, 16, 20, and 21) focused on Texas A\&M culture and events promoting BCS culture.

The revival of downtown Bryan, based on its history and its designation as a Downtown Cultural District (by the Texas Commission on the Arts in 2014), was hailed as a major achievement (by participants \#9, 11, 13, and 18 in the restaurant group, joined by \#10 Pedi-cab). Participants in the hotel group (\#5, 22, and 25) mentioned festivals that are linked to tourism, such as Texas Reds festival, Fiestas Patrias, Jazz Festival, and The World Festival all helped in fostering cultural pride within the community. An Arts Council staff member who worked as an exhibitor during the Texas Reds festival (2015) spoke about the significance of the festival: 
The festival brings a lot of economic benefits to the local community as the festival draws over 20,000 tourists over two days ... We treat all the tourists-local, out of town and others the same. We encourage everybody to become friendly, outgoing, to chat and interact with the tourists and to find out and serve what they are interested in.

All of the participants in the community/cultural group somewhat acknowledged that festivals promoted or contributed to the preservation of their community culture, history, and/or traditions. A participant/exhibitor in the Fiesta Patrias festival stated that the festival,

Helps to understand Mexican culture and heritage. It pulls the community together, helps businesses, as many businesses are local. It gives opportunity to talk to people. And all participants in the parade are volunteers.

Participants in the government group shared that the hotel occupancy tax (HOT) money supported organizing various festivals in BCS, which helped to preserve culture. The Brazos County official stated that tourism supported the African American Museum and its Heritage Journeys as well as the Jazz and Blues festivals. In the second group (backstage staffs), eight out of ten (8/10) participants emphasized the role of culture and festivals in attracting tourists to BCS.

Based on structured interviews with study participants (tourism stakeholders), formal, informal interviews conducted with various festival exhibitors and tourists, and participant observations of these festivals, it was found that festivals contributed to the preservation and promotion of various ethnic heritages, provided tourists a platform for interacting with locals and experiencing various cultures and foods. Local residents and exhibitors conceived festivals and events as an opportunity to share and interact with tourists, and tourists, in turn, exhibited an appreciation for the place visited, and showed respect for the natural/cultural quality and its appeal [1,2]. Further, various ethnic groups found these festivals as an expression and continuation of their culture and tradition. Festivals also created economic opportunities for the vendors and residents, and helped to enhance community cohesion through interactions and entertainment. It was an interesting finding that participants across various groups ( $\# 1,3,9,15,16,18,20,21,25,28,29$, and 30) emphasized that the Texas A\&M University culture and Aggieland Spirit symbolized the cultural diversity and rich tradition of BCS. Connections with Texas A\&M, bonding with the Aggie Spirit (Howdy!) were strong pull factors for its alumni and community.

\subsection{Educating Tourists about the Diverse History and Culture of the BCS}

Shared beliefs in forging emotional solidarity emphasizes preserving the local way of life, including the dining and entertainment facilities as well as engaging in similar behaviors alongside tourists involving pursuits focused on heritage and patronage of local businesses [10]. These factors are integral to both ethic of care as well as justice tourism as justice tourism is premised on supporting self-sufficiency and self-determination of local communities and supporting local economic, cultural, and social benefits [11,28].

Regarding educating tourists, some participants left this to the CVB, others thought that Texas A\&M University had a central role in educating tourists. Of those not working in a backstage capacity, most (i.e., 24 of 30) participants acknowledged that they or their staff were somehow engaged in providing information to incoming tourists about events, places to visit, and places to eat in BCS. Hotel participants (\#5, 9, 22, 24, and 25) were the most active in educating tourists, and participant \#25 stated:

But, any guest that come up and have a conversation with me and my front desk agents, that's what to do, try to show them with the Bonfire Memorial, which is like the heart of A\&M, that's the spirit of A\&M. We talk about how great $A \& M$ is ... If we get the opportunity to build relationship with them we recount our experiences, we recount the traditions. But, it's only through relationship that we get that opportunity. 
All of the participants in the cultural group conducted various activities in educating tourists about BCS history and culture. These activities included informing the tourists through partner restaurants, organizing lectures, conducting tourists' tours, mentoring staff, and for AAM (\#26)-hosting a booth at Texas A\&M events. In the government offices group, just two participants conducted educational activities, which included: displaying different events in rack-cards (by the George Bush Presidential Library); and, the Hall of Champions tour (at Kyle Field), and event venue tours by the TAMU Athletics Department. The Pedi cab participant (\#10) stated that he discussed Texas A\&M history and heritage with his customers during tours. Participant \#14 (a restaurant owner) stated that local residents "are proud tour guides" of the community. Of the backstage employees, few had opportunities for interacting, educating, and informing tourists due to their limited encounters with tourists. Only two staff in housekeeping and four participants in kitchen had the opportunity of informing tourists.

Results suggest tourism stakeholders in BCS often shared the history and heritage with their customers, which made it easy for tourists to positively contribute to the community. Such conducive behaviors from tourists were evidenced in the study, as tourists also complimented locals/stakeholders as the nicest/friendliest people (as reported by participants \#18 and 20), restaurant owners/staff received positive feedback from their tourists (\#21), and tourists expressed they had a good time and they valued services offered (\#13). A few participants suggested that tourists to BCS seemed to have been strongly influenced by the rich hospitality (e.g., Howdy! culture) of the staff and enjoyed the local food ( $\# 6$ and 23). Participants also suggested safe destination image and rich hospitality of stakeholders and residents made many tourists want to revisit $(\# 3,4,7,10,11,13,14,15,18,20,21,22$, $24,25,26$, and 28), move to (\#1, 2, 3, 7, 9, and 17), or retire (\#3, 8, and 17) in the BCS area.

BCS stakeholders generally shared their history and heritage with tourists in a respectful, fair, caring, and ethical manner, which helped to perpetuate the preservation of heritage and culture within the community. In turn, tourists showed interest in their culture, heritage, and cuisine, as manifested through repeat visits and participation in heritage/cultural activities. Tourists seemed to be motivated by the rich hospitality and caring attitude of stakeholders, which align with the criteria of ethic of care such as justice, fairness, equality, when considering the need of others, respect and beneficial activities for the host communities $[5,8,34-36]$ to some extent. Statements from the 40 participants reflect some of the activities of shared behavior and interaction, as outlined within the work of Woosnam, Norman, and Ying [2].

\subsection{Stakeholders Feeling Close, Mutual Understanding and Respect for BCS Tourists}

Participants representing restaurants believed that they had strong connections with customers (mainly local residents) by providing customer care (\#11 and 14) and demonstrating an understanding and respect for customers (\#18 and 20). Focusing on customer care helped to bring return tourists (\#11, 13, 18, and 20), including those to Southeastern Conference (SEC) football games (\#11). Some tourists also complimented locals/stakeholders as being some of the nicest/friendliest people (\#18 and 20), and locals were proud of Bryan working as guides (stated \#14). A restaurant owner (\#21) explained it in terms of customer loyalty:

We think of bonding maybe is to us that's loyalty maybe. And that to us is really measured by frequency, in really seeing people over and over again. We know that we are doing a good job for them and that they are enjoying their time here and that's how we get to know guests.

Participants in the hotel group also expressed strong bonding with tourists through good customer service (\#5, 9, 22, and 24), ensuring family/homey ambience in the hotel (\#22 and 24), and encouraging return visits (\#22, 24, and 25). Participant \#5, a hotel manager, related emotional solidarity as connectedness:

I am going to use a different word, I am going to use the word connected ... Forming those emotional bonds and we were no different than that. You know we want to provide a warm, welcoming environment for our guests; we want them to know we are here to serve them, we are here to take care of them, we are their home away from home. And to do that we have to form connections. 
The Brazos County official stated, "I find the tourists love this area. They love the people, they love the food, they love the opportunities, and the community loves the tourists".

Most participants (from the non-backstage participants) in the study replied that an aura of welcoming tourists to the BCS grew out of the Texas A\&M's friendly Howdy! culture. The Arts Council participant stated, "We roll out red carpets for them". From the responses of the first 30 participants, various dimensions of emotional solidarity were found to exist among the participants. For instance, encouraging a sense of welcoming was indicated by some participants, while at the same time, others conveyed that they understood tourists and what needs they had. A slight majority (i.e., 17 of 30 participants) claimed to have a strong bond with tourists. An official from the City of College Station said the perception of emotional solidarity is very strong, adding that, "We get very few complaints and very high compliments", while an official of the George Bush Presidential Library and Museum claimed, "They treat everybody with respect".

Participants in the housekeeping group also stated that they enjoyed a very strong bond with tourists (\#31, 33, 34, and 35), and added that tourists come back as a result. Participant \#36 stated they made tourists feel welcomed. In the kitchen group, participants (\#32, 37, 39, and 40) mentioned they shared a strong bond with tourists and three participants (\#32,38, and 40) claimed people came back because they like the food, hospitality, and festivals. Tourists liked staying in their hotel (\#33); and, one individual was sent a complimentary e-mail (\#36). Further, tourists complimented staff for being nice and polite (\#34). Participant \#38 stated, "I know like 10-12 families come every year to stay with us". Participant \#37 (executive chef) stated that tourists were treated well by staff.

According to the study participants, in general, the perception of emotional solidarity between the stakeholders (all types of hosts) and tourists (both local and out of the state) was thought to be rather strong in BCS. Stakeholders believe that they have developed 'family ties' with guests that foster a desire for tourists to return. Such statements reaffirm the friendly, hospitable destination image of BCS that is built on the foundations of feeling close, connected, and bonded with tourists. Only one negative aspect indicated by participants was the issue of game-day traffic (16/40 participants). However, participants (\#1,4,13,23, 28, 29, and 30) suggested that the community acknowledged the value of tourism and accepted congestion by coping in ways: leaving town, not visiting restaurants or places, and staying at home during these crowded times. Such small inconveniences paled in comparison to the economic contribution and community vibrancy following from tourism.

The study suggested a keen awareness of emotional solidarity with tourists [2,10], marked with mutual respect and understanding, ethical, fair, and virtuous behavior with concern and care for others-all the hallmarks of ethical tourism $[4,5,8,23,34,36]$.

\subsection{Stakeholders' Feeling Close, Mutual Understanding, and Respect for Local Tourists and Other Residents in the BCS}

It is the nature of restaurants worldwide that they cater to both local residents and out of town tourists, which is vital for their business and survival. The BCS restaurants emphasized customer care, which helped to bring return tourists (\#11,13,18, and 20), including those to Southeastern Conference (SEC) football games (\#11) and for other events such as Parents Weekends, Graduation Days, and Ring Days. Moreover, participants in the restaurants category in BCS indicated that they were highly dependent on local residents as customers. Therefore, these entrepreneurs and staff are equally concerned about providing quality services to all customers whether they are from out of the town tourists or from within the community customers. Numerous findings indicate that stakeholders perceive a strong sense of solidarity with local customers and out of town tourists alike.

In describing the relationship with tourists, the CVB representative (\#1) stated it is "very good". The Arts Council participant (\#3) echoed this sentiment claiming individuals in the downtown "are very connected" with tourists. Downtown Bryan has a "friendly atmosphere for all", according to the Lodging Association participant (\#4), as instituted by the Texas A\&M's Howdy culture. The Chamber of Commerce representative (\#2) stated that residents "understand" and "appreciate" the value of 
tourism, and the DBA (\#8) participant supported this notion by claiming, "This community is fairly welcoming" to tourists. Ethic of care in tourism, as discussed earlier [7,9], seems to be strong, as hosts believed that they take care of guests and that guests have a sense of respect, understanding, and caring attitude to their hosts.

In short, most of the participants replied that they experienced a close, coordinal, mutual understanding of, and respect for local tourists and residents (5/30 participants). In essence, relationships appeared to be strong with emotional ties (9/30 participants), as stakeholders indicated that they got along well with residents, enjoyed mutual support, and worked together (6/30 participants). Participant \#5 (a hotel property senior staff) stated, "There is a very strong connection between the residents and ... (the property) and that's in part because they see our name in all of their charity events". Another accommodations representative (\#9 a resort property senior staff) enjoyed "a deeper understanding and relationship" with local residents. Participants in the housekeeping group also stated that they enjoyed a strong sense of closeness with local residents and tourists (\#31, 33, 34, 35, and 36). Participant \#31 stated, "We're all sort of like a big ole' family when we have guests come in". Participants from the kitchen staff (\#38, 39 and 40) also mentioned that they enjoyed a very strong emotional solidarity with local residents and tourists. Positive statements from a majority of participants suggested that there was strong feeling of closeness, mutual understanding, and respect between tourists and local residents-all of which speak to a degree of community support contributing to sustainable tourism within the BCS.

The study suggested the perception of emotional solidarity among the tourism stakeholders and local tourists was guided by elements of strong bonding equivalent to family ties, mutual respect, and trust, which were carefully built on the foundation of customer services. A strong interconnection of elements of ethic of care (e.g., fairness, respect, and concern for others) between tourists and residents is prevalent in BCS tourism operations, and these feelings reverberate between residents and tourists, too.

\section{Discussion and Conclusions}

While the research involving both emotional solidarity and ethic of care is extensive within the tourism literature, the constructs have never been considered in tandem to examine their complementary aspects. As such, this novel research was undertaken to explore how the notions may be integrated and potentially reveal how destination planners, managers, and marketers can maximize community tourism benefits, tourists' satisfaction, and return visits by consolidating these complementary factors in their tourism planning and marketing.

This work highlights a host of insights intersecting emotional solidarity and an ethic of care. This study found that tourism stakeholders in BCS were proud of how the BCS culture, events, and Aggie tradition attracted tourists and how tourism helped in the preservation and promotion of their culture and tradition. Participants considered festivals and events to be an expression and continuation of their culture and tradition. Tourism made their city (Bryan) cleaner, more accessible, more interesting, and safer than in recent past years. Such positive statements, which can be associated with resident satisfaction, have implications for tourism managers and planners. This study supports the research by Ribeiro et al. [21] and Woosnam [1] that residents and tourists' satisfaction levels contribute positively to the development of a destination; the former garners support for tourism development and the latter results in word-of-mouth publicity and repeat visits. In a study from Quintana Roo, Mexico, Jamal and Camargo [9] revealed how residents of The Zona Maya have been deprived of ecocultural equity and ecocultural justice from government agencies, tourism boards, and investors, and how they have been subjected to ecocultural discrimination and ecocultural racism. Such practices that do not benefit the local residents with full potential may not receive local support, hence, jeopardizing the sustainability of tourism programs. That has not been the case in BCS tourism.

Tourism also served as a means of developing community pride and cohesion, as stakeholders were proud to inform tourists about attractions in BCS and even serve as guides. Such findings provide support for the notion that tourism development enhances community pride, sense of place and cultural/heritage preservation $[47,48]$. Efforts put forth by tourism stakeholders contributed to BCS 
being a viable place to relocate businesses or retire. Further, by paying due respect to the culture, tradition, and heritage of a visiting destination while being guided by a spirit of fairness, concern for others, respect for diversity, filled with a sense of justice, fairness, and equity $[4,5,34]$ can champion an ethic of care in tourism interactions. Ribeiro et al. [21] also asserted that socio-cultural interactions between tourists and residents enhance tourists' experiences and foster support for local culture, enhance solidarity and bonding, increase tourist satisfaction, all the while, encouraging revisitation through positive word-of mouth. The elements of EC and ES are found to be greatly operationalized in $\mathrm{BCS}$, which indicates a positive direction for its future tourism development in a sustainable manner.

Codes developed for ethical/justice tourism and more specifically, for ethic of care in tourism help sustainable tourism development as long as they are applied in practice. Such ethic of care included applying good, virtuous, ethical, just and caring behaviors, and actions in tourism interactions and transactions $[4,5,8,34-36]$. The study found that a majority of tourism stakeholders in the BCS either directly (i.e., personally) or indirectly (i.e., through their staff) were engaged in educating tourists about the diverse history and culture of the area. An impressive engagement from a majority of research participants for educating tourists exemplified that stakeholders are concerned with protecting their heritage as their ethical, moral duty. In return, as stated by some stakeholders, tourists were also found committed to the preservation of BCS way of living and culture through patronage, such as visiting festivals annually, seeking authentic cuisine in BCS restaurants, and wanting to return/relocate to BCS due to its good image and warm hospitality of its people/stakeholders. Other studies also emphasized that tourists' degree of connection and involvement with the destination [21] and emotional experience with the destination encourage future visitation [49]. Thus, the study findings support the earlier statements by Ribeiro et al. [21] and Woosnam, Dudensing, and Walker [50] that direct positive relationship and emotional solidarity of tourists with residents contribute to destination loyalty and satisfaction. The study findings supported the notion of an ethic of care largely as study participants placed emphasis on cultural preservation through educating tourists and information alongside economic benefits to the community accruing from tourism.

The sense of emotional solidarity tourism stakeholders perceived with tourists was very strong, and in some instances bordering on a relationship comparable to family members, stakeholders indicated that tourists also considered the hosts the 'nicest people' and they liked the local food and place. These dimensions of mutual understanding, respect, recognition, shared beliefs, and welcoming nature suggest a strong sense of emotional solidarity with tourists and ethic of care taking place simultaneously in BCS tourism. Local residents were the major source of customers for BCS restaurants except on major events, such as game days, graduation ceremonies, and parents' weekends. Some participants took game-day crowding as a temporal issue, but followed alternative coping mechanisms as they recognized the economic value of tourism. Restaurant and hotel participants iterated that they treated the local residents and tourists with an equal degree of warmth and care and they asserted they share a very strong bond with local residents and tourists. The study findings are in agreement with other findings that as long as residents and stakeholders get along well with a spirit of ethic of care $[4,5,8,34-36]$ and feel a bond with one another $[1,2,21]$ it positively impacts tourism development and its sustainable tourism future.

Woosnam's [1] work found support for the notion that "residents' attitudes about tourism and tourism development can be affected by and through the feelings and degree of solidarity that residents experience with tourists on an individual level" [1] (p. 10). This study resonates Woosnam's [1] findings and suggests tourism promoters, planners, and sports organizers (e.g., BCSCVB, TAMU Athletics Dept., CVB and city offices) need to take into account the perceptions of emotional solidarity of stakeholders/residents with incoming tourists to make BCS tourism community more sustainable and filled with ethic of care both for tourists and residents. This study provides feedback to local tourism planners and destination management organizations (DMOs) to make concerted efforts to build positive relationships between stakeholders/residents and tourists to the area through the exchange of mutual respect, understanding, and bonding. Suggestions from Woosnam [16] suggested 
that the more opportunities that exist for individuals to interact, the greater likelihood that they will have to understand one another.

Finally, the elements of the perception of emotional solidarity seem to closely complement the elements of ethic of care (justice tourism). This research further advances the idea that by integrating and promoting the sense of bonding and emotional solidarity between stakeholders/residents and tourists through mutual understanding and respectful and equitable behavior, tourism destinations may achieve greater social-cultural and economic benefits and remain closer to ethical and justice-oriented sustainable tourism development.

\subsection{Theoretical Implications}

This research has both theoretical and practical implications for academics and practitioners. It has been argued that a major criticism of sustainable tourism originated from a justice-oriented perspective (e.g., $[8,22,26,27])$. A close connection between ethics and justice in tourism has also been suggested (e.g., $[7,8,22,31])$, with particular emphasis on ethic of care pertaining to interactions and interrelations among residents and tourists [3,5]. Further, scholars, including Higgins-Desbiolles [28] and Scheyvens [11], championed enhancing mutual understanding, respect, trust, and reciprocity among residents and tourists through justice tourism. Other scholars $[1,2,19,20]$ emphasized establishing emotional closeness, mutual understanding and respect, and a welcoming attitude through shared beliefs, shared behavior and interactions. It can be seen that sustainable tourism development has been attempted separately either through ethical/justice tourism or through the application of emotional solidarity pertaining to host-guest interactions. This is the first study, which synergized ethic of care (through ethical/justice tourism) with emotional solidarity taking references from theory and practice and making it applicable for tourism research.

Since no past researches explored the complementing qualities of ES and EC, the primary contribution of this study lies in enhancing resident-tourist interactions and experiences with tourists applying various theoretical notions, such as emotional solidarity, ethic of care, and justice/ethical tourism together. The study supports past findings that shared beliefs, shared behaviors, and interactions between residents and tourists promote mutual understanding, respect, and welcoming attitudes among residents and tourists $[10,16,17]$. Further, the study also supports the earlier study outcomes that for a destination to be ethical and filled with ethic of care to its people and places, local tourism stakeholders, and incoming tourists are required to create an endearing environment that ensures justice, fairness, equality, respect to diversity, and concern for others [5,8,34-36]. A tourist destination that meets these minimum requirements can have a better path to sustainability and as per the study; BCS tourism broadly embraces such guidelines of emotional solidarity and an ethic of care. Further, contribution of this research in the form of recommendations to tourism policy makers and marketers to embrace both ES and EC in a complementary way have far-reaching positive implications for enhancing tourist-resident interactions for BCS tourism community in particular and other community tourism settings in general. Ethic of care when being interpreted as an alternative form of tourism has been more applied in developing countries [7,51-54] and current research in the United States (US) context increases the applicability of EC in both developing and developed tourist destinations in the world.

Ethic of care (ethical/justice tourism) and ES hold the potential to address some of the issues not fully addressed by sustainable tourism with limited prescriptions of socio-cultural, environmental, and economic sustainability [5] or the preponderance of neo-liberal hegemony that put 'ethics' on the sidelines [7]. As rightly pledged by Lovelock and Lovelock [5] and Smith and Duffy [7], ethical tourism filled with the notion of ethic of care is a better approach to sustainable tourism development, which this study has accomplished to some extent.

\subsection{Managerial and Practical Implications}

Tourist destination planning is often marred by issues of overlooked relationships between residents and tourists, hostile attitude of residents for tourism development, and failure of destination 
management organizations (DMOs) balancing such relationships [55]. Woosnam [16] opined that "It would be in the best interest of residents, tourists, and DMOs to assess relationships in a proactive manner using measures such as the emotional solidarity scale, with regular updates" [16] (p. 623) which reflected Hall and Lew's [12] perspectives on tourism development that a healthy and ongoing dialogue between residents and tourists should be encouraged. This research also relates to the model of destination development stages (euphoria, apathy, annoyance, antagonism), as proposed by Doxey [56], where residents' antagonistic perception of tourism development can lead to its eventual decline and/or death. Hence, it is important for DMOs, tourism managers, and planners to develop a feeling that residents and tourists share a greater sense of "welcoming nature, emotional closeness, and sympathetic understanding with one another" [16] (p. 624) that starts from the planning stage. Further, if such relations are negative, local managers and planners can host local tourism planning meetings so that residents can voice their perspectives and concerns regarding tourism development, which is also suggested by Gunn and Var [55] and Woosnam [16]. Further, organizing some special events and festivals where more opportunities exist for interactions between tourists and residents should occur [17]. Fortunately, the study found that no participant spoke about negative impacts of tourism in BCS, except game day crowding, which was perceived positively in terms of economic gains. This research found that some of the participants including those from ethnic minorities and backstage employees wanted more participation in tourism decision-making regarding BCS tourism. Possibly, destination planners and marketers in BCS can organize more participatory meetings to enhance decision-making and future tourism planning to better integrate the elements of ES and EC.

For tourism stakeholders engaged in tourism businesses, it will be an effective strategy to enhance emotional solidarity between residents and tourists through increased positive interactions by following ethical norms of mutual respect, understanding, trust, and caring attitude. These measures may enhance tourist satisfaction, and boost community incomes through visitation, as found in other studies [1,21]. As shown by the study, tourism events and festivals organized in the BCS have helped to boost destination image, preserve heritage and culture with an ethic of care, promote emotional solidarity between residents and tourists, and to create more economic opportunities in BCS. Therefore, it is up to the policymakers and planners to design and develop programs that further integrate and boost ES and EC to contribute to sustainable community tourism development. Possibly, launching formal educational programs to educate the tourism stakeholders and residents how adherence to ES and EC can further enhance positive resident-tourist interactions and inter-relationships can add to the foundation of sustainable community tourism.

Similar to earlier research findings [49,57,58], Ribeiro et al. [21] also emphasized, "Satisfied tourists are more likely to spread positive word-of-mouth about the destination to potential tourists and to revisit" [21] (p. 12). Woosnam and Aleshinloye [59] pointed out that positive relationships between tourists' emotional solidarity and tourists' satisfaction and destination loyalty could contribute to increased visitation by tourists. Several participants' assertions that tourists wanted to return to BCS, relocate their business, or retire there bear significant implications for future tourism growth provided tourism planners in BCS develop policies and implement actions to continue and increase tourist satisfaction through increased resident-tourist interactions. Further, Woosnam [17] argued if a DMO is aware and informed that degree of emotional solidarity and bonding between residents and tourists is very strong; it helps them to launch marketing programs, which can stimulate greater visitations and revisits. DMOs can modify their promotional campaigns and update their websites with statements how residents embrace tourists in a very positive way.

\subsection{Limitations and Directions for Future Research}

Though this research is unique in synergizing the complementary elements of ES and EC for destination development through improved resident-tourist interactions and interrelations, it is not free from limitations. Application of ES factors, which was mostly applied in quantitative studies [2, 10], has been used as a point of reference (not applied or replicated exactly) for this qualitative 
exploration. Therefore, the findings of this study may not be replicable for other destinations though they provide rich insights combining the notions of ES and EC and exploring them in a vibrant tourism community, such as BCS within Texas. Further, this study included a limited number of 40 tourism stakeholders from BCS and did not include residents and tourists; though it is worth mentioning that 39/40 stakeholders claimed themselves to be local residents. Therefore, findings of this study can provide perspectives from the tourism stakeholders' side only. Any future studies, which concurrently involve multiple stakeholders of tourism, such as residents, tourists, management, and working staffs (e.g., representing kitchen, housekeeping, and other backstage jobs), tourism academicians and tourism policy-making bodies, can bring better insights. Another limitation of the study is that it included three major ethnic groups only-White, Hispanic, and African American as BCS study participants. However, other ethnic groups, such as American Indian or Alaska native alone and Asian alone, which consist of $0.4 \%$ and $2.3 \%$ of population in Bryan and $0.2 \%$ and $9.7 \%$ of population in College Station, respectively [60], were not a part of this study. Therefore, the inclusion of other ethnic minorities in addition to three dominant ethnic groups can be suggested for future studies to bring richer perspectives representing all major and minor ethnic groups. Concerning another shortcoming of the study, possibly, by adding another specific question for study participants how they believed they could improve the perception of emotional solidarity and ethic of care with tourists (though they found it to be strong) contributing to destination development, their specific suggestions would have been helpful in improving overall tourism development in BCS. Hall and Lew [12] suggested that ongoing dialogue from residents/stakeholders regarding how they feel about tourists and destination development (even though it is normally positive) is important for DMOs for planning sustainable tourism operations. Further, combining such qualitative exploration with predictive, measureable quantitative studies in the future would enhance its reliability and replicability.

EC is a broad concept and it also looks into other aspects, such as living standards and wages of tourism workers, opportunities for their career growth (promotions), economic benefits to local communities, (including ethnic minorities/indigenous people), employment opportunity for local people, job-related trainings, and so forth. However, these aspects were not included in this paper as they did not directly relate to tourist-resident interactions and they were not comparable to ES and EC, which were the main thesis of this research. However, future studies that emphasize issues, such as tourism workers' living standards and wages, opportunities for their career growth (promotions), and economic benefits to local communities, (including ethnic minorities/indigenous people), and integrating these issues through the lenses of ES and EC hold potential for improving tourism workers' current working conditions and existing tourism practices. Further, based on the recommendations of this study that tourism policy makers and marketers need to embrace both ES and EC in a complementary way for achieving far-reaching positive implications for sustainable tourism operations, additional studies are required in other geographical and cultural contexts to bring a more comprehensive and cross-sectional insights into this new research agenda. Scholars who generally focus on three dimensions of sustainability: social, economic, and environmental for the success and sustainability of tourism businesses need to blend one additional humanistic agenda of sustainability that embodies both ES and EC $[1,3,5-7,10]$ together. In the context of earlier studies pointing out the gap between researchers, policy-makers, and practitioners concerning sustainable tourism development [61,62], integrated application of ES and EC concerning sustainable tourism development could potentially bridge such gaps to some extent, which seems to be a fertile ground for future research.

Funding: This research received no external funding.

Conflicts of Interest: The author declares no conflict of interest 


\section{References}

1. Woosnam, K.M. Using emotional solidarity to explain residents' attitudes about tourism and tourism development. J. Travel Res. 2011, 51, 315-327. [CrossRef]

2. Woosnam, K.M.; Norman, W.C.; Ying, T. Exploring the theoretical framework of emotional solidarity between residents and tourists. J. Travel Res. 2009, 48, 245-258. [CrossRef]

3. Fennell, D.A. Tourism Ethics; Channel View Publications: Bristol, UK, 2006.

4. Jamal, T.; Camargo, B.A.; Wilson, E. Critical omissions and new directions for sustainable tourism: A situated macro-micro approach. Sustainability 2013, 5, 4594-4613. [CrossRef]

5. Lovelock, B.; Lovelock, K. The Ethics of Tourism: Critical and Applied Perspectives; Routledge: New York, NY, USA, 2013; pp. 1-368.

6. Shiva, V. Staying Alive: Women, Ecology and Development; Zed Books: London, UK, 1989; pp. 1-234.

7. Smith, M.; Duffy, R. The Ethics of Tourism Development; Routledge: New York, NY, USA, 2003.

8. Hultsman, J. Just tourism: An ethical framework. Ann. Tour. Res. 1995, 22, 553-567. [CrossRef]

9. Jamal, T.; Camargo, B.A. Sustainable Tourism, Justice and an Ethic of Care: Toward the Just Destination. J. Sustain. Tour. 2014, 22, 11-30. [CrossRef]

10. Woosnam, K.M.; Norman, W.C. Measuring residents' emotional solidarity with tourists: Scale development of Durkheim's theoretical constructs. J. Travel Res. 2010, 49, 365-380. [CrossRef]

11. Scheyvens, R. Tourism for Development: Empowering Communities; Prentice-Hall: Harlow, UK, 2002.

12. Hall, C.M.; Lew, A. Understanding and Managing Tourism Impacts: An Integrated Approach; Routledge: New York, NY, USA, 2009.

13. Mason, P. Tourism Impacts, Planning and Management, 2nd ed.; Routledge: New York, NY, USA, 2008.

14. Aramberri, J. The Host Should Get Lost: Paradigms in the Tourism Industry. Ann. Tour. Res. 2001, 28, 738-761. [CrossRef]

15. Harrill, R. Residents' attitudes toward tourism development: A literature review with implications for tourism planning. J. Plan. Literat. 2004, 18, 251-266. [CrossRef]

16. Woosnam, K.M. Comparing residents' and tourists' emotional solidarity with one another: An extension of Durkheim's model. J. Travel Res. 2011, 50, 615-626. [CrossRef]

17. Woosnam, K.M. Testing a model of Durkheim's theory of emotional solidarity among residents of a tourism community. J. Travel Res. 2011, 50, 546-558. [CrossRef]

18. Durkheim, E. The Elementary Forms of the Religious Life; Free Press: New York, NY, USA, 1995.

19. Woosnam, K.M.; Maruyama, N.; Boley, B.B. Perceptions of the 'Other' residents: Implications for Attitudes of Tourism Development Focused on the Minority Ethnic Group. J. Travel Tour. Market. 2016, 33, 567-580. [CrossRef]

20. Woosnam, K.M.; Aleshinloye, K.D.; Maruyama, N. Solidarity at the Osun Osogbo sacred grove-A UNESCO world heritage site. Tour. Plann. Dev. 2016, 13, 274-291. [CrossRef]

21. Ribeiro, M.A.; Woosnam, K.M.; Pinto, P.; Silva, J.A. Tourists' destination loyalty through emotional solidarity with residents: An integrative moderated mediation model. J. Travel Res. 2017, 61, 523-537. [CrossRef]

22. Tribe, J. Education for ethical tourism action. J. Sustain. Tour. 2002, 10, 309-324. [CrossRef]

23. Macbeth, J. Towards an ethics platform for tourism. Ann. Tour. Res. 2005, 32, 962-984. [CrossRef]

24. Jafari, J. Research and scholarship: The basis of tourism education. J. Tour. Stud. 1990, 1, 33-41.

25. Bramwell, B. Governance, the state and sustainable tourism: A political economy approach. J. Sustain. Tour. 2011, 19, 459-477. [CrossRef]

26. Dangi, T.B. Towards a Robust Framework of Sustainable Community-based Tourism (SCBT): Exploring Destination Justice and Equity as a Part of Governance, a Case Study of Bryan-College Station, Texas. Ph.D. Thesis, Texas A\&M University, College Station, TX, USA, 2016.

27. Dangi, T.B.; Jamal, T. An integrated approach to "sustainable community-based tourism". Sustainability 2016, 8, 475. [CrossRef]

28. Higgins-Desbiolles, F. Justice tourism and alternative globalisation. J. Sustain. Tour. 2008, 16, 345-364. [CrossRef]

29. Higgins-Desbiolles, F. International solidarity movement: A case study in volunteer tourism for justice. Ann. Leisure Res. 2009, 12, 333-349. [CrossRef] 
30. Strambach, S.; Surmeier, A. Knowledge dynamics in setting sustainable standards in tourism-the case of 'Fair Trade in Tourism South Africa'. Curr. Issues Tour. 2013, 16, 736-752. [CrossRef]

31. Lee, S.; Jamal, T. Environmental justice and environmental equity in tourism: Missing links to sustainability. J. Ecotour. 2008, 7, 44-67. [CrossRef]

32. Rawls, J. A Theory of Justice; The Belknap Press of Harvard University Press: Cambridge, MA, USA, 1999.

33. Rawls, J. Justice as Fairness: A Restatement; Kelly, E., Ed.; The Belknap Press of Harvard University: Cambridge, MA, USA, 2003.

34. Josephson Institute. 12 Ethical Principles for Business. Available online: http://josephsononbusinessethics. com/2010/12/12-ethical-principles-for-business-executives / (accessed on 22 November 2017).

35. Schumann, P.L. A moral principles framework for human resource management ethics. Hum. Res. Manag. Rev. 2001, 11, 93-111. [CrossRef]

36. United Nations World Tourism Organization (UNWTO-GCET). Global Code of Ethics for Tourism. Available online: http:/ / ethics.unwto.org/en/content/global-code-ethics-tourism (accessed on 28 July 2018).

37. Texas A\&M Today-2016, Texas A\&M Has Record Fall Enrollment of 66,426. Available online: https://today.tamu. edu/2016/10/13/texas-am-has-record-fall-enrollment-of-66426/ (accessed on 27 November 2017).

38. Blinn College, Blinn Surpasses 19,000 Students, Sets New Enrollment Record. Available online: https:/ / www.blinn.edu/news/2014/september/new_enrollment_record.html (accessed on 28 July 2018).

39. Texas Office of the Governor, Economic Development and Tourism Division-2015, Texas Tourism Region and MSA Tourist Profile, Prepared by D. K. Shifflet and Associates, Ltd. Available online: http:/ travel.texas.gov/tti/ media/PDFs/2014-Prairies-and-Lakes-Region.pdf (accessed on 28 July 2018).

40. Bryan College Station Convention and Tourists Bureau (BCSCVB). Business and Marketing Development Plan, 2014-2015; Bryan College Station Convention and Tourists Bureau: Bryan, TX, USA, 2015.

41. Oxford Economics-2012, The Economic Impact of Texas A\&M University Home Football Games. Available online: http:/ / wtaw.com/wp-content/uploads/2012/09/OxfordKyleFieldPpt.pdf (accessed on 28 July 2018).

42. Bernard, H.R. Social Research Methods: Qualitative and Quantitative Approaches; Sage Publications Inc.: Los Angeles, CA, USA, 2013.

43. Marshall, C.; Rossman, G.B. Designing Qualitative Research; Sage: Los Angeles, CA, USA, 2011.

44. Hsieh, H.F.; Shannon, S.E. Three approaches to qualitative content analysis. Qual. Health Res. 2005, 15, 1277-1288. [CrossRef] [PubMed]

45. Birks, M.; Mills, J. Grounded Theory; Sage: Los Angeles, CA, USA, 2011.

46. Bryant, A.; Charmaz, K. Grounded theory in historical perspective: An epistemological account. In The Sage Handbook of Grounded Theory; Bryant, A., Charmaz, K., Eds.; Sage: Los Angeles, CA, USA, 2010.

47. Goeldner, C.R.; Rithie, J.R.B. Tourism Principles, Practices, and Philosophies; John Wiley and Sons Inc.: Hoboken, NJ, USA, 2009.

48. Wall, G.; Mathieson, A. Tourism: Change, Impacts, and Opportunities; Pearson Education: New York, NY, USA, 2006.

49. Prayag, G.; Hosany, S.; Odeh, K. The Role of Tourists' Emotional Experiences and Satisfaction in Understanding Behavioral Intentions. J. Destin. Market. Manag. 2013, 2, 118-127. [CrossRef]

50. Woosnam, K.M.; Dudensing, R.M.; Walker, J.R. How does emotional solidarity factor into tourist spending among birders in the lower Rio Grande Valley of Texas? J. Travel Res. 2015, 54, 645-658. [CrossRef]

51. Goodwin, H. Indigenous tourism and poverty reduction. In Tourism and Indigenous Peoples: Issues and Implication; Butler, R., Hinch, T., Eds.; Elsevier: Philadelphia, PA, USA, 2007.

52. Goodwin, H. Taking Responsibility for Tourism; Goodfellow Publishers Limited: Woodeaton, UK, 2011; pp. 1-256.

53. Fair Trade in Tourism South Africa (FTTSA), 2005, Principles and Criteria for Fair Trade in Tourism. Available online: http:/ /iatp.org/files/271_2_78102.pdf (accessed on 28 July 2018).

54. Fair Trade Tourism Annual Report 2012/2013. Available online: http:/ / www.fairtrade.travel/Annual--Reports / (accessed on 28 July 2018).

55. Gunn, C.A.; Var, T. Tourism Planning, 4th ed.; Routledge: New York, NY, USA, 2002.

56. Doxey, G.V. A causation theory of visitor-resident irritants: Methodology and research inference. In Proceedings of the 6th Annual Conference on Travel Research Association, San Diego, CA, USA, 8-11 September 1975.

57. Baker, D.A.; Crompton, J.L. Quality, Satisfaction and Behavioral Intentions. Ann. Tour. Res. 2000, $27,785-804$. [CrossRef] 
58. Engeset, M.G.; Elvekrok, I. Authentic Concepts: Effects on Tourist Satisfaction. J. Travel Res. 2015, 54, 456-466. [CrossRef]

59. Woosnam, K.M.; Aleshinloye, K.D. Can tourists experience emotional solidarity with residents? Testing Durkheim's model from a new perspective. J. Travel Res. 2013, 52, 494-505. [CrossRef]

60. United States Census Bureau. Quik Facts, College Station city, Texas; Bryan city, Texas; United States. Available online: https:/ / www.census.gov/quickfacts/fact/table/collegestationcitytexas,bryancitytexas,US/PST120217 (accessed on 28 July 2018).

61. Gössling, S.; Hall, C.M.; Weaver, D. (Eds.) Sustainable Tourism Futures: Perspectives on Systems, Restructuring and Innovations; Routledge: New York, NY, USA, 2009.

62. Johnston, C.S. Towards a theory of sustainability, sustainable development and sustainable tourism: Beijing's hutong neighbourhoods and sustainable tourism. J. Sustain. Tour. 2014, 22, 1-19. [CrossRef]

(C) 2018 by the author. Licensee MDPI, Basel, Switzerland. This article is an open access article distributed under the terms and conditions of the Creative Commons Attribution (CC BY) license (http://creativecommons.org/licenses/by/4.0/). 